\title{
¿MÁS POEMAS DE BARTOLOMÉ LEONARDO DE ARGENSOLA?
}

No deja de ofrecer cierta curiosidad el hecho de que los mejores manuscritos que han transmitido obras poéticas del Barroco sean los de los admiradores de Góngora y los de los Argensolas. Son manuscritos mucho más rigurosos que los de los restantes poetas, como si la atención de los lectores se hubiera polarizado en dos tendencias: la gongorina y la neoclásica, representada por los aragoneses. Abundan, claro, y yo soy el que menos lo puede olvidar, las copias de poemas de un Quevedo, pero ninguna se aproxima en rigor siquiera a las de Góngora $o$ a las de Lupercio y Bartolomé Leonardo, cuyas Rimas, editadas por Gabriel Leonardo de Albión en 1634, tampoco son completas, aunque ya el editor confiesa que "ha sido igualmente difícil para mí que pudiera serlo para un extraño" el recoger los poemas. Por esta causa yo pude añadir en mi edición ${ }^{1} 54$ poemas de Lupercio y alrededor de 90 de Bartolomé que figuraban en manuscritos muy autorizados y de cuya autenticidad cabían pocas dudas, puesto que más de una vez se trataba de respuestas a otros poemas.

Hoy traigo aquí otro códice de cuya existencia ha dado noticia el maestro Dámaso Alonso en su libro sobre la "Epistola moral a Fabio"', manuscrito que nunca había sido citado por los estudiosos y que es, a su vez, el que contiene más poemas auténticos de Bartolomé Leonardo, lo que justificaría esta nota.

Se trata de un estupendo códice, copiado en 1630 por don Julián Arias de Rueda, que perteneció a la biblioteca del Duque de Medinaceli y hoy para en la de don Bartolomé $\mathrm{March}^{3}$ bajo la

1 Rimas de Lupercio y Bartolomé L. de Argensola, Zaragoza, 1950-1951.

2 La "Epistola moral a Fabio", de Andrés Fernández de Andrada. Edición y estudio, Madrid, 1978, pp. 280-282.

3 Agradezco mucho a don Bartolomé March las facilidades dadas para su estudio, lo mismo que a doña María Dolores Vives, encargada de la biblioteca. 
signatura 23-4-8. Consta de diez folios iniciales sin numerar, destinados a la portada e índices de primeros versos, más 643 páginas con numeración de la época. En 4:, todo de una misma letra, salvo los folios 2 y 3 que son de un excelente pendolista. En la portada se lee: † / Obras / Bartholome / Leonardo de Argensola / Capellan de la emperatriz / doña Maria de Austria / Y Rector de Villa hermosa / Y oy Canonigo de la S. ${ }^{\text {ta }}$ / Yglessia de Caragoza y / Chronista de su Magd / año 1630. En el folio siguiente se encuentra la $\dagger$ / Tabla de / los Versos que estan en / este quaderno. Escriuiolos para / si, don Iulian Arias de Rueda / y los acabo de juntar a Once / de febrero de Mill y seisçientos y treinta / años

[Firma autógrafa] Don Julian / Arias de Rueda / Ay algunos versos de Lupercio Leonardo

A continuación se copia el índice de los primeros versos por orden alfabético.

El manuscrito contiene un total de 185 poemas, pero el copista advierte al margen de los sonetos 41,52 y 56 que están duplicados (por ser versiones distintas) y anota también que los tercetos del 65 son iguales a los del 71. No indica que los poemas 78 y 92 son de Lupercio, pero sí lo dice en los poemas 98 y 157-167, con la particularidad de que debió de enterarse más tarde, a juzgar por cómo los transcribe, colocando el nombre y el apellido a los lados de "Terçetos", "Satira", así: Luperçio Terçetos Leonardo (núm. 165), Luperçio Satira Leonardo (núm. 166), lo que prueba muy claramente que en principio los poemas se copiaron como de Bartolomé, aparte de que los rasgos de la letra, aun de una misma mano, son más recios, hecho que también se puede com probar con la indicación final de la tabla anterior. Pero es más curiosa la nota que figura al frente del soneto 96, "Aquel que pudo, Fabio, aquel que pudo", que dice así: "Este soneto me a dicho D. Luis de Ulloa que es suyo"4, lo que indica que nuestro Arias de Rueda debió de enseñar a don Luis de Ulloa su copia.

Esto nos lleva a su vez a otras atribuciones, como la de la Epistola moral a Fabio (núm. 130) y la de la célebre canción "Ufano, alegre, altivo, enamorado" ", que evidentemente no son poemas de Bartolomé Leonardo. Tampoco lo son el romance que comienza "Los que quisieren saber" (núm. 156), atribuido en

- En efecto, figura en los Versos que escrivio D. Luis de Ulloa y Pereira, Madrid, 1659, p. 21.

- Para las atribuciones, véanse mis notas "La canción «Ufano, alegre, al. tivo, enamorado" y "El autor de la canción «Ufano, alegre, altivo, enamorado" en Sobre poesia de la edad de Oro, Madrid, 1970, pp. 244-256. 
diversas ocasiones a Quevedo" y el delicio Baile "Reberencia os hago / vella vizcayna" (núm. 168). Sin embargo, aun con la certeza de no ser de Bartolomé Leonardo, puesto que además el principio figura en Los Prados de León, de Lope de Vega?, yo lo edito más adelante por no haberlo encontrado completo en otra parte. Edito también los poemas que parecen inéditos, pero no aseguraría que sean realmente del Rector de Villahermosa, sí que pueden ser suyos por los temas y el estilo. Lo curioso es que no se hallen en los demás códices, pero tampoco figuran otros, como el núm. 81, que coincide con la versión de las Rimas.

Tampoco aparecen en los otros manuscritos muchos de los epígrafes a numerosos poemas, algunos muy curiosos, con la particularidad de haberse puesto después de copiar los poemas, utilizando los espacios en blanco entre uno y otro, que normalmente contienen la indicación de Soneto 1, Soneto 2. Esto parece apuntar a la posibilidad de que don Julián Arias de Rueda viese después otros manuscritos y añadiese los epígrafes.

Copio seguidamente el índice de los poemas que contiene el manuscrito por el mismo orden en que aparecen, y más adelante edito los poemas desconocidos, conservando la ortografía original, pero con la acentuación y puntuación de hoy.

José Manuel Blecua

Barcelona.

\section{CONTENIDO DEL MANUSCRITO}

1 Soneto 1/ Yo aquel que un tienpo, aunque con rrudo estilo .... 1

2 Soneto 2/ Más alterado el mar, más inquïetos ............. 1

3 Soneto $3 / \mathrm{Ya}$ el oro natural crespes o estiendas ............. 2

4 A un amigo que se canse de esperar /Soneto 4/ Probecho hallarás, Fabio, en la tardanza ....................... 3

5 Soneto $5 / A \quad D$. Nuño de Mendoza, enseñándole dos retratos [de] Heráclito y Demócrito /De los dos sabios son estos retratos ...... 4

6. Contra una dama que hacia muy malos versos /Soneto [6]/ Dejan

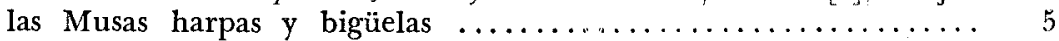

7 Soneto $7 /$ Tanto a podido un pensamiento honesto .......... 6

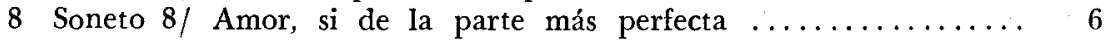

9 Soneto $9 /$ De antigua palma en la suprema altura .......... 7

10 A una muger que hablaua un honbre muy al oydo, ella muy afeytada y él muy barbado y ençendido de narizes/Soneto $10 / \mathrm{Si}$ tan

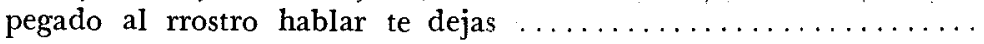

6 Véase en Obras poéticas, t. 3, Madrid, 1971, p. 154.

7 En la edic. de la Real Academia Española, t. 7, Madrid, 1897, p. 149b. 
11 Soneto $11 /$ Cremes, regala a Liçe y no çelebres .............

12 Soneto 12/ A la canpana de Belilla, quando se tocó el año de [1]611. Contra un descuydado / El metal sacro en Julia Gelsa suena.

19 Soneto $13 /$ Señor, a eterno ayuno me dedico ...............

14 Soneto $14 /$ Creçe deprisa, poderossa ierba $\ldots . . \ldots \ldots \ldots \ldots \ldots$.

15 A un amigo que traya la barba demasiadanente larga, con que le pareçía enseñaua las letras /Soneto 15/ ¿Cómo tienes notiçia

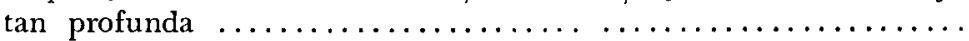

16 A unos que litigauan sin más interés que su rencor el uno con el otro /Soneto 16/ ¿Por qué hauitáis, ladrones homiçidas .....

17 A un hombre muy peruersso, a quien, al parezer, se tardaua Dios nuestro señor en el castigo /Soneto $17 / \mathrm{Si}$ a los buenos sacaba el

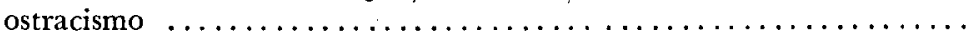

18 Soneto 18/A un hombre de muy mala vida / Ya no murmura el

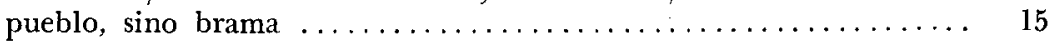

19 Soneto $19 /$ Pues tú con ta[nta] propiedad desdeñas ......... 15

20 A una dama que sin beber vino le olia mal la boca /Soneto 20/ Si nunca Baco y sienpre fuente uiua $\ldots \ldots \ldots \ldots \ldots \ldots \ldots \ldots$

21 Desengaños a Hernández de lo mal que le pareze en todo tienpo y lo que la quicre /Soneto $21 /$ Fili, yo te aborrezco de manera..

22 A una dama que se preçiaua del amor plotónico quando se sauia trataua del lasçiuo demasiadamente/Soneto $22 /$ Gala, no alegues

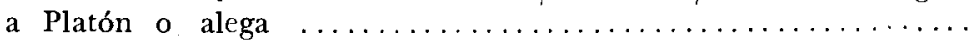

23 A un médico que creyó era remedio preseruatiuo del adulterio poner una rana viua en la camisa del menstruo de su muger, segun Pli[nio] /Soneto 23 / En la olanda vañada del tributo .........

24 Soneto 24/ Aunque Obidio te dé más documentos .............

25 A la oraçión del Huerto /Soneto 25/ ¿Qué estratagema haçéis, guerrero mio ............................... 20

26 Soneto $26 /$ ¿Qué máxica a tu voz venal se iguala .............

27 Soneto $27 /$ Pues no sienpre tus rayos vengatiuos ............

28 Soneto $28 /$ Bilbilis, si te dio el señor de Delos ...............

29 Entrando en Guadalaxara en dia que enterrauan al duque del Infantado y a un hijo de un mesonero /Soneto 29/ Llego a Gua-

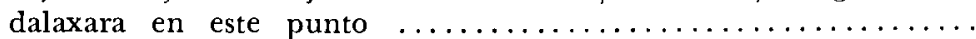

30 Soneto $30 /$ Dime, Padre común, pues eres justo ............

31 A la muerte de Cristo, nuestro redemptor y confusión de todos /Soneto 31/ Oy, por piedad de su haçedor quisieron ..........

32 De doña Catalina de Solis al Rector, dejándole en Salamanca /Soneto $32 /$ Mientras goçamos con igual contento ..............

33 Respuesta del Rector con los mismos consonantes /Soneto 33/

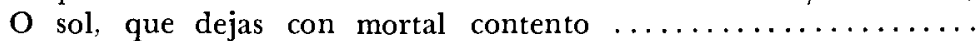

34. Del padre Juan Luis de la Zerda al Rector/Soneto 34/ El arte

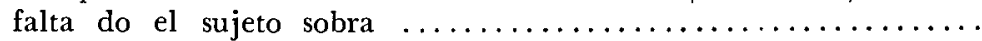

35 Respuesta en los mismos consonantes de[l] Rector/Soneto 35/ El

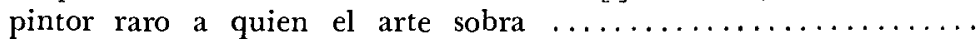

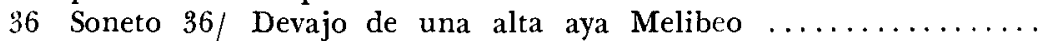

37 An amigo, pintándole una muger hermosia, aunque sin juiçio /Soneto 37/ Liçe es aquella, acude, Fausto, y mira ..........

38 Reconbençión al descuydo de nuestra vida/Soneto $38 /$ Tendrás,

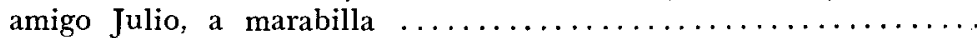

39 Atribuye la mexoria de una enfermedad a vna dama hasta clla 
esquiua /Soneto 39/Viéndome Fili en manos de la muerte ....

40 A una dama de muy buen uliento de boca /Soneto $40 /$ Fili, al

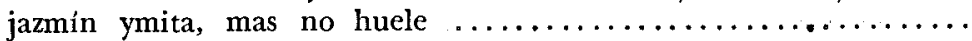

41 Que haçe mal quien fía en la contingençia de lo futuro /Soneto 41/

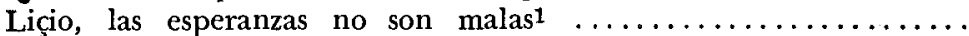

42 Contra los que pronostican por las rayas de la mano /Soneto 42/

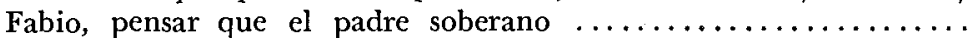

43 Enseña a una dama, en el retrato de Mario, la inconstançia de las cosas humanas y lo que se mudan con el tienpo /Soneto 43/ Mario

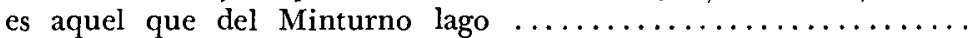

44 Pintura de su vida filósofa y sin anbiçion /Soneto 44/ Vistome lo

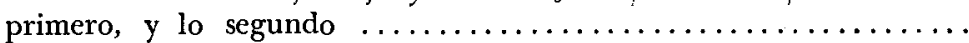

45 A Tajo, quando sale a él Hernández/Soneto 45/ Tajo, produ-

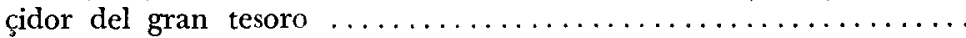

46 Efecto de valor, acreditase en el trauajo antes que en las prosperidades /Soneto $46 /$ Es para ti la esfera de la luna ..........

47 Que no se quexe antes. Dé gracias a Dios quien no ha tenido trauaxos considerables /Soneto 47 / No con el vulgo, acuses, o Liçinio.

48 De Juan Ripol al Rector de Villahermossa /Soneto 48/ Si el sú-

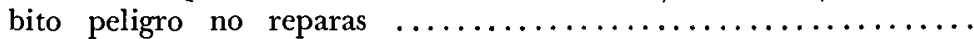

49 Respuesta del Rector en los [mismos] consonantes/Soneto $49 / \mathrm{O}$ tú,

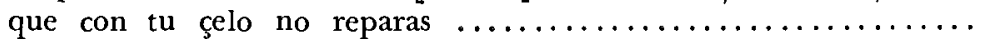

50 A la duquesa doña María de Aragón quando salió de menina y se puso chapines/Soneto 50/ Quando el Amor sus flechas aprestaua.

51 Al naçimiento del Príncipe nuestro señor en Viernes Santo, ocho de abril de [1]605/Soneto 51/ Ya la Asia vemos a tu imperio unida.

52 Al Duque de Villahermossa D. Carlos de Borja /Soneto 52/ Carlos,

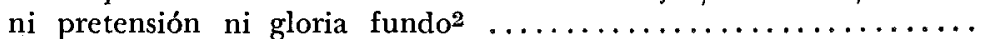

53 A un astrólogo y contra la facultad /Soneto 53/ Bástale al dia

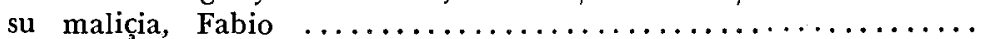

54 Pregunta a su razón si podrá vençer sus afectos desordenados/Soneto $54 /$ ¿Será possible que a mis manos muera ..............

55 Crédito a la verdad en passión amorosa /Soneto 55/ A llegado

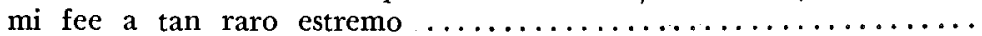

56 La parte superior de nuestra naturaleza vençida de una passión /Soneto 56/ Bien sé yo, Cintia, el culto que se deue $3 . . . \ldots \ldots$

57 Desengaño a una dama en las cossas naturales /Soneto 57/ Cloris, este rosal que libre o rudo $\ldots \ldots \ldots \ldots \ldots \ldots \ldots \ldots \ldots \ldots \ldots \ldots$

58 Pide a Dios nuestro señor el auxilio eficaz/Soneto $58 /$ ¿En qué

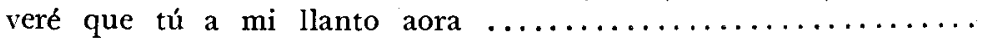

59 Da razón a un amigo porque continúa unas amistades dañosas al parezer /Soneto $59 /$ Estos amigos tibios exercito ............

60 A un amigo que no deje vençer la parte superior con acuerdo de su nobleza /Soneto 60/ El honbre fue de dos principios hecho ..

61 Pretende con fuerza de verdad venzer a Gutiérrez /Soneto 61/ Hago,

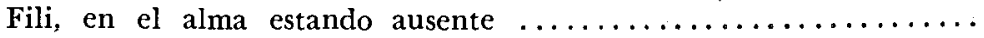

$62 A$ los que se tiñen las canas/Soneto 62/ Incor[r]egible Néstor, de los años

1 Al margen: "Duplicado a fo 61. Fabio".

2 Al margen: "Otro a fo 601 , con los mismos consonantes y conçepto".

3 Al margen: "Duplicado a fo 73. Fili, bien sé". 
63 Soneto $63 /$ Lauso, a qui[en] su raiz teme algún pino ..........

64 A un caballero, a quien mato un rayo, de uida culpable demasiadamente /Soneto 64/ Lico, aunque Dios los pérfidos permite ..

65 A la natiuidad de Nuestro Señor /Soneto 65/ Oy rompe amor los

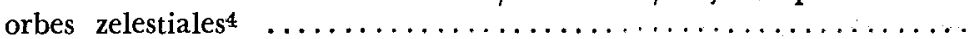

66 A D. Fernando de Borja, virrey de Aragón /Soneto 66/ Pues tu

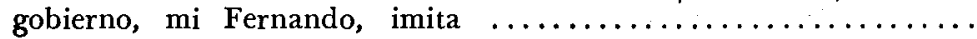

67 Pintura del sitio en que se puso a dormir D. N. y rresistençia fingida y para qué /Soneto 67 / Rendida Clori de una ardiente siesta.

68 Liçençiado Juan Jordán al Rector de Villahermossa /Soneto 68/ Rector muy docto, a quien a dado el çielo ..................

69 Respuesta del Rector con los mismos consonantes/Soneto 69/ $\mathrm{Si}$ llegar pienso con mi frente al çielo ......................

70 Reducción en una enfermedad y deprecaçión a Dios nuestro señor /Soneto $70 / \mathrm{Si}$ un afecto, Señor, puedo ofreçerte .............

71 A un mal médico; cossa común y sienpre uista /Soneto 71/ Tú, a

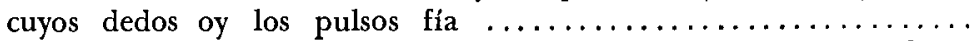

72 A un juez que castigó a un honbre para cometer el mismo delito él /Soneto $72 /$ Visto el proçesso y autos dél fallamos ...........

73 A la esperanza y el tiempo/Soneto 73/ Fabio, las esperanças no

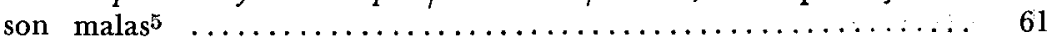

74 Soneto $74 /$ Ter[r]eno en cuyos sacros manantiales .......... 62

75 A las ruynas de diferentes probinçias /Soneto 75/ Ministra fue del

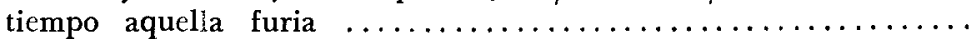

76 Contra la destreza rreduçida a ciencia /Soneto 76/ Quando los

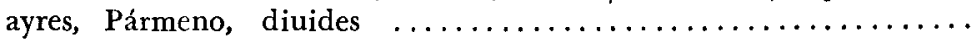

77 Al naçimiento de Cristo nuestro redemptor/Soneto 77/ Dios vaja

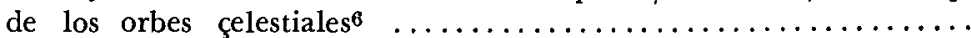

78 La vida de Miclas, acreditada contra la de Alexandro /Soneto 78/ Descuydado del lauro que ennobleçe ..................

79 Insta a Alexandro y culpale las passiones /Soneto 79/ Mira, Alexan-

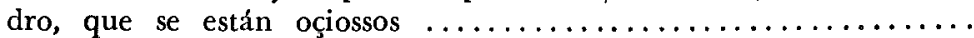

80 Soneto $80 /$ Mírame con piedad y arda el cometa .............

81 A uno que blasonaua de una pasión amorosa /Soneto 81/ ¿Estás

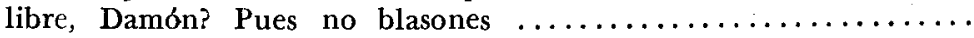

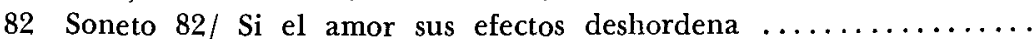

83 A la Asumpçión de Nuestra Señora a los cielos /Soneto 83/ Oy, real Señora, hasta la inpírea esfera ................... 69

84 Soneto $84 /$ Fili, de la intención pura y honesta ........... 70

85 A un caballero a quien mató un rayo día en que auía comulgado, de cuya desgraçia preçedió que un esclauo suyo se baptiçase luego /Soneto 85/ Tu fe, Guzmán, lidió en los çielos tanto ......... 71

86 Soneto $86 /$ ¿Quién me dará jazmines y violetas ............ 72

87 Pide a Filis rretribuçión con exemplos naturales/Soneto $87 / \mathrm{Si}$

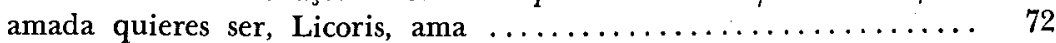

88 Soneto $88 /$ Fili, bien sé que todo el culto deue $\ldots \ldots \ldots \ldots \ldots \ldots 73$

4 Al margen de los tercetos: "Estos tercetos están a f? 64".

5 Al margen: "Duplicado a fo 34, Liçio".

6 Al margen de los tercetos: "Estos tercetos están en el soneto a la Natiuidad, f. 54".

7 Al margen: "Duplicado a fo 46, Bien sé yo Çintia et".". 
89 A una dama que se teñia. Consejos y desengaño /Soneto 89/ Pon,

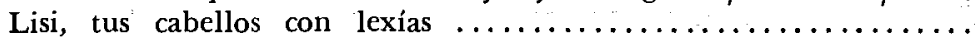

90 A una dama que finxía faborezer / Soneto 90/ Con tiránicas leyes

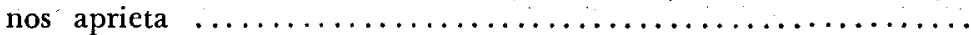

91 A una dama. Sus partes y perfeçiones /Soneto 91/ Los soplos de Fa-

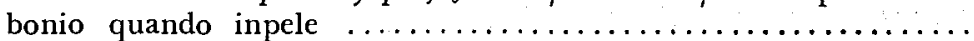

92 A una dama que con mirarse vea sus rrigores/Soneto 92/ En el luçiente espejo que aora tienes $\ldots \ldots \ldots \ldots \ldots \ldots \ldots \ldots \ldots \ldots \ldots . \ldots \ldots \ldots$

93 Aconseja a un amigo que alcanzará más con el marido de vna dama que con ella /Soneto 93/ En la edad de oro, aunque vbo afectos

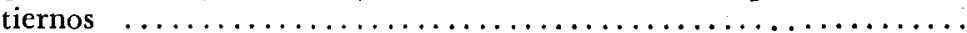

94 Consejo a un amigo que es conueniente el aplauso popular/Soneto

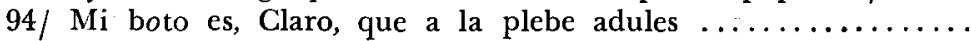

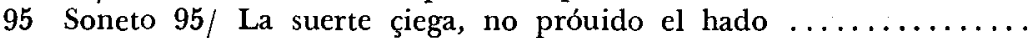

96 Soneto $96 /$ Este soneto me a dicho $D$. Luis de Vlloa que es suyo I Aquel que pudo, Fabio, aquel que pudo ................

97 A la inconstançia de las cossas humanas /Cançión/Vfano, alegre,

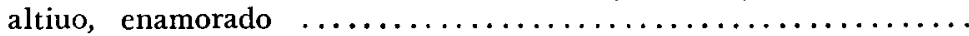

98 En el zertamen del Santísimo Sacramento /Lupercio/ Después que

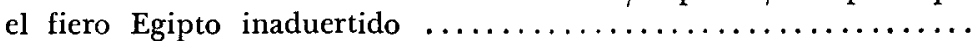

99 A la purissima conçepción de Nuestra Señora /Cançión l/ A todos

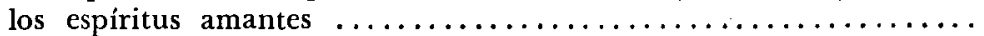

100 A san Ramón, obispo de Balbastro, en la traslaçión de sus reliquias /Cançión 2/ Oy quiere el çielo que de su Raymundo ......

101 Psalmo "Super flumina etc a" /Cançión 3/ Algunas vezes se nos

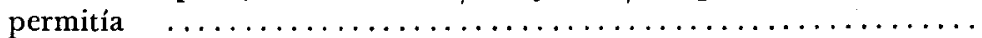

102 A la primauera /Cançión 4/ De los campos y mares se apodera ..

103 Discurso de la razón contra el apetito /Cançión 5/ Apenas hiço la

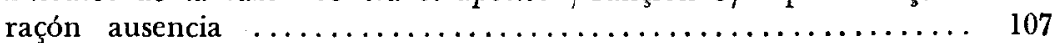

104 Al rey Felipe 3 en las obsequias de su padre /Cançión 6/ Pues las deuidas lágrimas vertiste $\ldots \ldots \ldots \ldots \ldots \ldots \ldots \ldots \ldots \ldots \ldots \ldots \ldots . \ldots \ldots$

105 Cançión 7/ Quando me paro a contenplar mi estado ......... 122

106 Traducçión del himno "Jesus corona Virginum" / Jesús, corona del virgíneo coro ............................. 127

107 De los santuarios de Zaragoça. Al rey nuestro señor Felipe 3! /Cançión $8 /$ En tanto que nos haze tu esperanza ................ 129

108 A santa María Magdalena /Cançión 9/Aquella pecadora que solía. 140

109 A la naue de la Yglessia /Cançión $10 /$ Ȳa la primera naue fabricada

110 A Sant Lorenzo /Cançión 11/ Mártir dichosso, que con presto buelo.

111 A la Assumpçión de Nuestra Señora/Cançión 12/ Mártires y don-

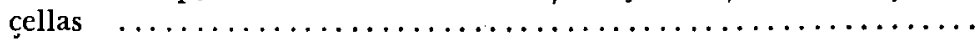

112 A las exequias que hizo la Vniuersidad de Zaragoça al rey Felipe 20, como la del Petrarcha que comienza "Mai no voi piu cantar com yo soleua". Diose en el nonbre de Luis Estratón y es de el Rector. Está en el libro recojido por el Abad de Sant Juan de la Peña, Martínez, fo 108 /Cançión 13 / No quiero yo cantar como solía .......... 164

113 A Sant Laurencio /Octauas 1/ Más cruel espectáculo que quando .. 169

114 Al comendador mayor de Montesa, D. Fernando de Borja, por el Rector de Villahermossa Bartolomé Leonardo de Argensola / Para uer acosar toros valientes

$115 A$ un amigo estudiante. El Rector. Preceptos de escriuir versos/Ter. 
çetos/ Don Juan, ya se me a puesto en el zeruelo ............ 200

116 Fsalmo "Quam dilecta tabernacula tua Domine virtutum etca" / E1

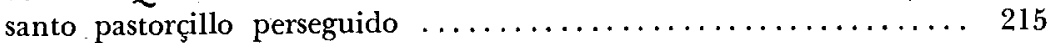

117 Himno de la gloria / Ad perenis vitae fontem... /Terçetos/ Corre a la fuente de la eterna vida ..................... 219

118 A Sant Raymundo /Terçetos/ Domadas ya las islas Baleares ..... 227

119 A Euterpe, escusándose de las pretensiones de las cortes / Tales consejos das, Euterpe mía? ........................ 232

120 A don Nuño de Mendoça, disuadiéndolo que no trayga sus hijos a la Corte /Terçetos/ Díçesme, Nuño, que a la Corte quieres ...... 257

121 Al Marqués de Zerraluo. Respuesta del Rector/Terçetos/ No te pido perdón de auer tardado $\ldots \ldots \ldots \ldots \ldots \ldots \ldots \ldots \ldots \ldots \ldots . \ldots \ldots 7$

122 Don Françisco de Borja a Bartolomé Leonardo /Terçetos/ Señor

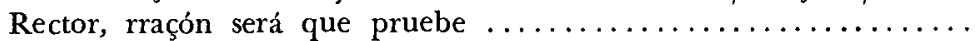

123 Respuesta de Bartolomé Leonardo /Terçetos/ Don Francisco, aun-

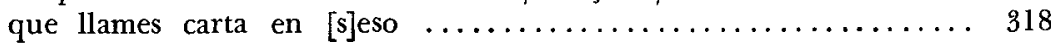

124 Alonso Esq[u]erra a Bartolomé Leonardo /Terçetos/Desta cassa del Nunçio propiamente $\ldots \ldots \ldots \ldots \ldots \ldots \ldots \ldots \ldots \ldots \ldots \ldots . \ldots 26$

125 Respuesta del Rector por los mismos consonantes/Terçetos/ Pues

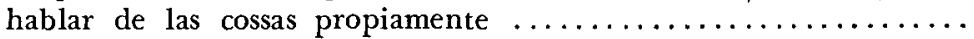

126 Traduciones de Oracio / Satira 9. Libro 1/ Ibam forte uia sacra, etca I Yendo por la uia sacra acaso un día ....................

127 A don Francisco de Eraso/Tercetos/Oy, Fabio, de la Corte me

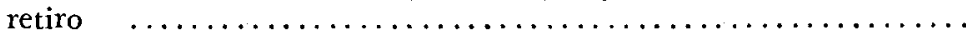

128 Al conde don Francisco de Castro/Terçetos/Joben real por el

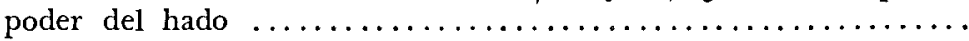

129 Elegía en la muerte del conde de Gelues/Terçetos/ Cayó, señor, rendido al açidente $\ldots \ldots \ldots \ldots \ldots \ldots \ldots \ldots \ldots \ldots \ldots \ldots \ldots \ldots$

130 A un amigo pretendiente / Terçetos/ Fabio, las esperanzas cortesanas. 384

131 En las exequias de la reyna señora nuestra que se çelebraron en Nápoles, año de 1611 /Elegía en terçetos/Con feliz parto puso al

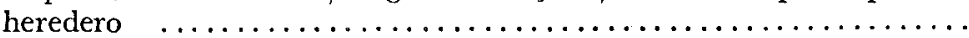

132 Al relox dentro de un globo sobre un gigante de plata y oro que sirue en la cámara del señor conde de Lemos/Terçetos/ $\mathrm{O}$ tú, en cuya zeruiz la fuerza estriba $\ldots \ldots \ldots \ldots \ldots \ldots \ldots \ldots \ldots \ldots \ldots \ldots \ldots \ldots \ldots \ldots \ldots \ldots$

133 A Fernando de Soria Galbarro /Terçetos/ Yo quiero, mi Fernando,

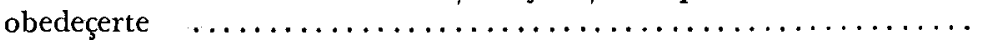

134 Contra la mentira. Sátira en terçetos / Inclínense a tu nombre, o gran Ribero ............................. 426

135 A la Fortuna. Horatio, Lib. 1, 0.35/Liras/O diossa, tú que rijes ..

136 Oda 7a Quid fles, Asteriae. Lib. 3o /Liras/ ¿Por qué, Asteria, te

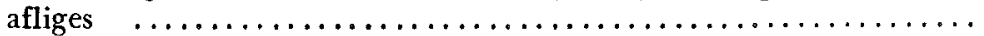

137 A Mario. Liras / Quien uiue con prudençia ...............

138 A la primauera. Liras / Fili, naturaleza ..................

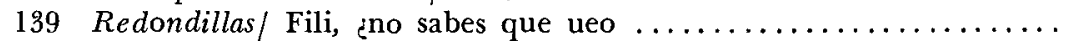

140 Déçimas/ Aunque ocupen mi secreto $\ldots \ldots \ldots \ldots \ldots \ldots \ldots \ldots$

141 Déçimas/ Apriétame de manera $\ldots \ldots \ldots \ldots \ldots \ldots \ldots \ldots \ldots \ldots$

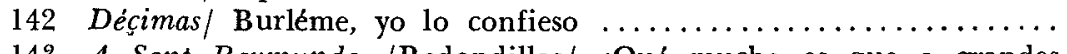

143 A Sant Raymundo/Redondillas/ ¿Qué mucho es que a grandes

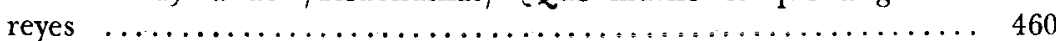

144 A la tierra de el sepulchro de Sant Raymundo /Redondillas/ Glosa / Ay en esta peña fuerte .................... 464 
145 A la adoración de los Reyes/Cançión/ La estrella que hasta en-

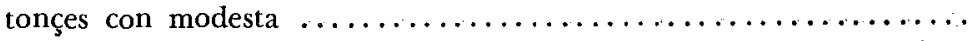

146 Al arçipreste Ram. Psal. 118 / Anima mea in manibus / No induçe neçesidad

147 A Liçe. /Décima/ Viéndose en un fiel cristal .................

148 Distico de Ausonio / Infelix Dido, nullo bene... / Dido infeliz,

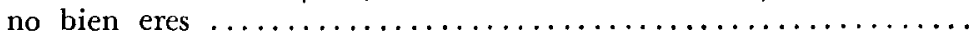

149 Epigrama de Marçial / Si quando leporem... / Traduçión del Rector / Quando una liebre me enuías ................. 473

150 Marçial / Inscripsit tumulo... / Traduçión / Cloe, la séptima vez.

151 Marçial / Scripsi, rescripsit... /Traduçión/ Escriuí, no a respon-

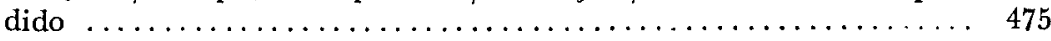

152 A un letrado de sólo aparienzia / Si uos pretendéis que venga ... 476

153 Ad Eliam. Marcial / Quatro dientes te quedaron ..............

154 Satisfaze a un[a] quexa de una dama [por] no haçerle versos/Redondillas/ Mil quexas, niña, me has dado .............. 477

155 Redondillas/ Bella Amarilis, en tanto ................. 481

156 Sátira de viçios comunes /Romanze/ Los que quisieren saber ....

157 A la fiesta de S. Diego en Alcalá de Henares, estando en ella D. Felipe segundo, nuestro señor / Luperçio Leonardo /Cançión/ En es-

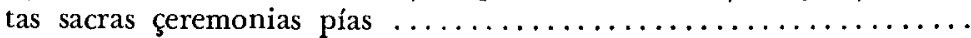

158 A Sant Françisco. De Luperçio Leonardo /Cançión/ Tan ofendido

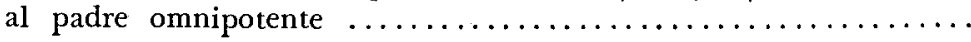

159 A Sant Laurençio / De Luperçio Leonardo /Cançión/ ¿A quién no

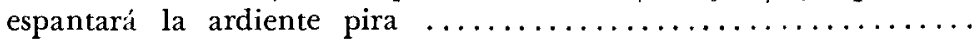

160 A la ver [da]dera amistad. [De Lupercio Leonardo] /Cançión/ Aque-

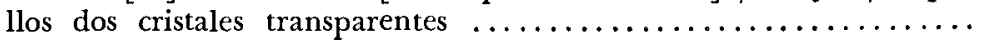

161 A los çinco sentidos / De Luperçio Leonardo. Cançión/ En tanto que gozauan mis sentidos ....................... 509

162 Cançión. Luperçio Leonardo / Estas seluas veçinas . . . . . . . . . . 517

163 A un mal parto / Luperçio Leonardo /Cançión/ Arroja la corona. 521

164 Descripçión de Aranjuez / De Luperçio Leonardo /Terçetos/ Ay un lugar en la mitad de España ................... 524

165 Respuesta y etimoloxia deste nombre Bárbaro / Luperçio Leonardo /Terçetos/ Obediente rrespondo a la pregunta ............. 535

166 Lupercio Leonardo / Sátira a las cortesanas, en primer lugar a Flora, en tercetos/ Muy bien se muestra, Flora, que no tienes ........ 542

167 De Luperçio Leonardo / Terçetos a un amigo, su nombre D. Juan/ Aquí donde la suerte de Ponpeyo .................. 568

168 Bayle/ Reberençia os hago ...................... 594

169 Déçima al libro de la Fundaçión de Santa Teresa / Bien probáys que quien se humilla $\ldots \ldots \ldots \ldots \ldots \ldots \ldots \ldots \ldots \ldots \ldots \ldots \ldots$

170 A una dama que le tiró vna bala de zera verde llena de agua de azaar /Déçima/ Dulçe señora, no hallar .............. 597

171 A Bartolomé Leonardo quando le hiçieron canónigo. Epitafio /Déçima/ Siste el grado, caminante .................... 598

172 Respuesta del Rector en los [mismos] consonantes/Déçima/ No rrepares, caminante ........................... 598

173 A la ocasión de los galeones que llegaron a Cádiz el año de [1587] /Soneto 97/ Aunque entre naues, o Bretaña ingrata ...........

$174 A$ don Carlos de Borja, duque de Villahermossa /Soneto 98/ Ni 
opinión, Carlos, ni esperanza fundo $8 \ldots \ldots \ldots \ldots \ldots \ldots \ldots 601$

175 A sancta Teresa de Jesús /Soneto 99/ A su Teresa Cristo en uisión clara ....................................... 601

176 A Bartolomé Leonardo, un amigo /Soneto 100/ Fabio, el manjar que del inpíreo çielo ............................... 602

177 Respuesta de Bartolomé Leonardo /Soneto 101/ $\mathrm{Si}$ al que en alas de zera subió al çielo ............................ 603

$178 A$ un presumido de saber todas las çiençias siendo ignorante /Soneto 102/ ¿Quién podra, Lauso, ver quan sin rrespeto ........... 604

179 A San Eufrasio en su traslaçión /Cançión/ Oy vuelue a los abrazos

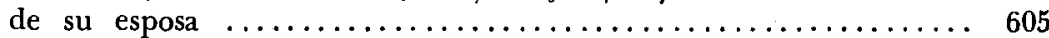

180 A Sant Miguel /Cançión/ Pues no ay voz ni estilo suficiente ... 609

181 Carta de D. Fernando de Auila a Bartolomé Leonardo en que le pide saque a luz sus versos /Terçetos/ Quando a las cossas públicas

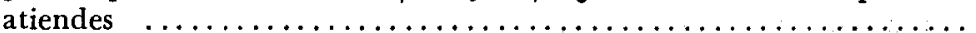

182 Respuesta de Bartolomé Leonardo escusándose/Terçetos/ ¿El título me das de tu maestro ............................. 632

183 Soneto 103 / Luego que naçe el pensamiento mío ............. 641

184 Soneto 104 / Fabio, sin unión falsa o verdadera .............. 641

185 Soneto $105 /$ Esté el que se pagare poderosso ............... 642

\section{TEXTOS}

La suerte çiega, no próuido el hado, destinó a vuestros ojos çelestiales color con que aperçibe a los mortales que quien los uiere mire recatado.

5 Fue piedad de superior cuydado que asistan del peligro en los unbrales agüeros precursores de los males que limiten al más aventurado.

$\mathrm{Su}$ estrago el fuego en el color sangriento

10 a la aueçilla que le sigue aduierte y el luto a mí en el vuestro desengaños.

Bien deue, Fili, del ossado intento costossas experiençias a la muerte quien no reçela preuenidos daños.

8 Al margen: “A f? 43 ay otro soneto al mismo intento con estos consonantes y conçepto". 
CONTRA LA MENTIRA

Sátira en terçetos

Inclínense a tu nombre, o gran Riber[i]o, las criaturas más nobles y perfectas que ay en la redondez del emisferio, pues huyendo del mundo las sujetas

5 y rebates la furia poderossa de los contrarios siglos ${ }^{*}$ y planetas.

Dichosso tú, que, en tu cabaña hermossa, gozas de los regalos y labores de la inbidiada soledad dichossa.

10 La qual, como el antojo, haçe mayores el gusto de auitar en los jardines, cogiendo trutos en lugar de flores.

Que puesta entre arrayanes y jazmines, como antes se calienta que se entiuia,

15 sin passar por los medios va a los fines.

Dichosso tú, que no te fuiste a Libia, ni al monte inaccesible do el gigante del gran peso de estrellas no se aliuia; ni en las remotas Indias del Leuante

20 te vestiste las pieles erizadas del tigre, de[1] león, del elefante;

ni en las cabernas de la Çitia eladas fuiste a ver el lugar donde se cría la confusión de sierpes enrroscadas; ni buscaste en Egipto la momia, que sólo por ser hecha de hombres muertos es la más apaçible conpañía.

Antes, en vez de hallar en los desiertos la santa soledad que en la aspereza

30 tiene lugares dedicados ciertos,

la buscas entre el gusto y la nobleza con tanta discreçión y conpostura que descubres tu ingenio y tu agudeza.

Pero en qualquier lugar está segura,

35 porque la soledad no está en lugares, sino en el coraçón que la procura.

Que en medio de los tráfagos vulgares, a quien sirue el engaño y la mentira; como en un edifiçio, de pilares, 
40 puede el varón que ser piudente aspira tener la soledad más verdadera si dentro de sí mismo se retira.

Que el rüydo del mundo es de manera que le uiene a dejar como a la gente

45 que hauita del gran Nilo en la ribera.

$\mathrm{Y}$ porque más te agrade $\mathrm{y}$ te contente este argumento, quedará probado con una razón clara y euidente:

y es, que assí como el mar alborotado

50 suele estar, aunque brabo y rigurosso, en su profundo abismo sosegado,

y como el ayre fiero, tenpestuosso, está quando despide más bramidos en medio de su esfera con reposso,

55 assí, en los alborotos y rüidos, quando son con extremo, ay un silençio que deja a los mortales suspendidos.

Yo soy quien esta uida reberençio,

60 porque a faboreçerme jamás venga, en lugar de un Meçenas, un Mesençio.

Mas, ¿de qué a de seruir que yo le tenga tan peregrino amor, si en todo el orbe no ay a quien satisfaga ni conbenga?

65 Ni quien la entrada ni el camino estorue a un ardiente resuello que el profundo suele arrojar quando las almas sorbe.

Dél a naçido un monstruo sin segundo, que entre unas medio brujas, medio viejas, 70 desde pequeño se crió en el mundo.

$\mathrm{Y}$ como todo es cuentos y consejas. por palillo le lleuan en las bocas y a ueçes por zarçillo en las orejas.

Las gentes tiene con su engaño locas

$75 \mathrm{y}$ es tan afeminado hermafrodita, que tiene barbas y se pone tocas.

¡O mentira cruel, que estás escrita en la abrasante puerta del Infierno, como aranzel de su opinión maldita!,

80 ¿quién te dio de los hombres el gobierno, que los persigues, fiera y espantable, con duro azote vengatiuo, eterno?

Por ti, en el mundo triste y miserable, todo lo que no es çielo soberano 
85 suele decir mentira, aunque no hable.

Porque miente el ibierno y el verano quando con sus efectos desiguales suelen desconponer el cuerpo humano.

Tanbién diçen mentira las señales

90 de una cossa muy çierta y muy sabida y mienten los sentidos corporales.

Los ojos porque en cossa conoçida la uerdad por su culpa no dijeron; la boca porque estuuo desabrida.

95 Muchos por el olfato se perdieron, y el patriarca Isac, zercano a muerte, los oydos o manos le mintieron.

También suele mentir la humana suerte, pues estando sujeta al albedrío,

100 muchas ueces se trueca y se preuierte.

Pero jómo podrá el injenio mío nauegar a las Indias que desseo, si ay en tan poco mar tanto vaxío?

Tantas mentiras en el mundo ueo,

105 que la verdad, de uerlas infalible. me pareze mentira y no la creo.

Tratemos lo primero, si es possible, de la difiniçión marauillossa deste nonbre espantable, aborrecible.

110 Mentira propiamente es una cossa que el padre que la enjendra la procura pintar de modo que parezca hermossa; mas quando se descubre su figura, queda tan fea, flaca y maçilenta, que el hacedor se corre de su hechura.

115 Pues sin caer entonzes en la cuenta, suele haçer una cossa que si alguno determina deçírselo le afrenta.

Deste manjar cruel, fiero, inportuno, queda, por tar de su deleite indiçio,

120 el que está más ahito, más ayuno.

No procuro infamar con este uiçio al offiçial auaro que procura en haçelle instrumento de su offiçio; ni al que deste Aspilcueta se confía,

125 y assí la ropa que a uendido cara la conpra él mismo y otra vez la fía; ni al que en uender su haçienda no repara 
pessada en la balanza deste peso

o medida en los terçios deste vara;

ni al que suele tener tan poco seso,

que con el corte desta pluma escribe

las fidedignas ojas de un proçeso;

ni al que leyendo en este libro uiue

de dar un pareçer tan inportante,

135 que viene a perezer quien lo reçiue.

Destos no será justo que me espante,

porque ay entre ellos hordinariamente

un pobre, un loco, un triste, un ignorante.

$\mathrm{Y}$ tiene por çertíssimo esta jente

140 que en este mundo de miserias lleno no se puede uiuir si no se miente.

Los que yo más acuso y más condeno son aquellos que tienen, quando infaman, vómitos de ponzoña y de veneno.

145 Y si por dicha alguna vez los llaman para paçificar una fatiga agua en el fuego de alquitrán derraman.

Estos conuiene mucho que persiga, pero con todo es menester que calle,

150 pues tan poco diré, por más que diga.

Porque en la plaza pública, en la calle, en el lugar desierto, en el poblado, en el río, en el monte y en el valle,

de mentiras el ayre está quaxado,

155 que, como son vapores, se lebantan para formar de males un nublado.

Ya de deçir mentira no se espantan los que suelen tenella por propiçia, que a todos en deçilla se adelantan.

160 Mentira suele auer en la miliçia, en la haçienda, en la honrra, en la nobleza y alguna vez tanbién en la justiçia.

Mentira suele auer en la pobreza, en la fee, en el amor, en la esperanza, en la curiosidad, en la agudeza.

Mentira suele auer en la alabanza de vanas y sofísticas razones, en la sobrada giıla, en la tenplanza.

Mentira suele auer en las passiones,

170 en las mal conoçidas amistades, en las bien alentadas pretensiones. 
$\mathrm{Y}$ en fin, por rematar sus calidades, en mí, por lo que tengo de poeta, es mentira tanbién deçir verdades.

175 Dichossa el alma que no está sujeta, Riberio, a la costumbre desta vida, que está en predicamento de perfeta.

Yo la tengo de oy más aborreçida con tanto estremo, que de hablar con gentes

180 cassi lo más del tiempo se me oluida.

Quisiera, entre culebras y serpientes, haçer mi auitaçión, por dar señales de que son mis costumbres diferentes.

$\mathrm{Y}$ assí, llorando alguna vez mis males,

185 acreçiento las aguas deste río, que no es caudal y haze ganar caudales.

$\mathrm{Y}$ pues[to] en el gobierno, amparo y brío, con gallardos caprichos y quimeras, el alto eterno pensamiento mío,

190 si uees al mayoral destas riberas, los pies le vesa de mi parte, y dile que ninguno le sirue con más ueras.

$\mathrm{Y}$ que aunque mis seruiçios aniquile, no hallará con razón más verdadero

195 en la distancia que ay de España a Chile;

donde con el fabor del tiempo espero estanpar su blasón, único y raro, en reluçientes láminas de azero o en transparentes mármores de Paro.

REDONDILLAS

Fili, ¿no saues que ueo que el poder de un dios limitas, quando a Liçina acreditas porque su amador es feo?

5 No quiere Amor que se deje su offiçio por la raçón, ni permite a la raçón que con ella se aconseje.

No fíes de presunçiones,

10 ni enuaneçidos despreçios, que es seguridad de neçios poner el gusto en razones.

$\mathrm{Y}$ el penetrar y el sauer todo se turba y se çiega, 
15 porque quando el hado llega nos combiene obedeçer.

El todo que más desplaze, si por sus partes se aduierte, haçe el odio menos fuerte

20 y a ueçes nos satisfaçe.

Çibalis, noble donçella cuyas bellezas acallo, amor fue ya de un caballo que criaua el padre della;

25 Leda rindió sus cuydados a un çisne que la burlaua y el negro pico aplicaua a sus labios colorados;

Pasife, con hebras de oro

30 y hermosura sin par, muchos la uieron llorar por los desdenes de un toro;

a un feo y vasto elefante Sofronia entregó su pecho

35 y en el estrado y el lecho la trataua como amante.

Fili, assí la edad passada, con este filosofar, se enseña* a poderse amar qualquiera cossa tratada.

$\mathrm{Y}$ tú, muy cándida y fiel, fías de Liçina bella, pudiendo el discurso della menos que la dicha dél.

$45 \quad \mathrm{Y}$ anssí, entre estas diferençias, quiero callar y sufrir:

que es mucho mejor morir que afrentossas conpetençias.

Esto uasta para ti;

50 que saues quanto presumo, mientras se reduze a humo la ilustre llama en que ardí.

Mas no reste ni aun pabor en fuego tan ofendido;

55 sea çeniças de oluido quanto fue brasas de amor.

Enmudezcamos la fama

* Se enseña, habria que leer te enseña. 
que esperaste de mi fe;

Cubra el inçendio que ardía, émulo de Mongibelo, fría nieue y torpe yelo, por su honrra y por la mía.

65 Muera secreto el dolor; no uengan a ser mis quejas lisonja de las orejas deste tonto vençedor.

G. Reberençia os hago, vella vizcayna, que no ay en Vizcaya donçella más linda. que esos ojos miran, y esas manos blancas son prisiones mías.

Más quisiera veros, mi querida amiga, que uenzer los moros de la Berbería.

D. Yd con Dios, el conde, mirad que soy niña, que temo los hombres que andan por la villa.

Si lo saue madre, a fee que me rriña: que no trate en almas, sino en almohadillas.

Que allí doy puntadas; que apunto mis dichas matizando sedas que alegran la uista.

25 G. Vámonos, mi alma; vámonos, mi vida, a la mar, que traygo quatro naues mías.

Coxióla en sus brazos y a la mar camina; 
metióla en su naue;

dize "Zarpa", "Yza".

D. ¡Ay, Dios!, que me lleua;

ןay, Dios!, que me obligan;

35 adiós, patria amada; adiós, madre mía.

G. No lloréys, mi alma; no lloréys, mi vida;

que vertéis sin causa

esas perlas finas.

Si os lleuo forzada, no os lleuo cautiua;

uos me captiuastes

el alma y la uida.

Lléuoos a ser dueño

de las tierras mías,

donde, como a mí,

os amen y siruan.

Con esto mostróse

50 más bella que esquiua: sienpre el Amor vençe en tales porfías.

Díçele "Mi alma"; rresponde "Mi vida".

55 Perdonad, señora, si estáis ofendida.

Luego que naçe el pensamiento mío de su misma uirtud se ue pagado; que no es mi pensamiento el derriuado, sino yo, que en sus méritos me fío.

Esfuerza el coraçón, alienta el brío, y voy con el exemplo a ser osado, hasta que en la miseria de mi estado para en conoçimiento el desuarío.

Mas ¿qué ynporta mi daño al pensamiento,

10 las ansias uiuas, la esperanza muerta, lastimosa piedad y amarga historia,

si por naturaleza uiue esento de pena y de temor, en gloria çierta, unido al ser de uida el ser de gloria? 
SONETO 105

Esté el que se pagare poderosso del palaçio en la cunbre deleznable; a mí dulçe quietud me lleue amable, puesto en lugar obscuro más dichoso.

5 Oçio süaue goçe y laborioso; de mí jamás se escriba, ni se hable; corra mi edad su curso ineuitable, sin que pase por día sumptuoso.

Quando, tranquilo y uiejo, esté cunplida [p. 643]

10 la ora postrimera, aperçeuido, goçoso tomaré lo que uiniere.

Porque aquel sentirá perder la uida que siendo en todo el mundo conoçido sólo de sí desconoçido muere. 